\title{
“LA POSICION ORDINAMENTAL DE LOS REGLAMENTOS ORGANICOS DE LAS ENTIDADES LOCALES TRAS LA SENTENCIA 214/1989, DE 21 DE DICIEMBRE, DEL TRIBUNAL CONSTITUCIONAL"
}

\author{
POR \\ Manuel Jesus Sarmiento Acosta \\ (Abogado, Becario-investigador del Instituto Canario de \\ Administración Pública y de la Función Universitaria de Las Palmas. \\ Profesor Asociado de Derecho Administrativo de la Universidad de \\ las Palmas de Gran Canaria)
}

SUMARIO: I. Consideraciones Generales.- II. La Potestad autoorganizaTORIA COMO ELEMENTO IMPRESCINDIBLE DE LA AUTONOMIA LOCAL.- 2,1) Determinaciones previas. 2,2) Tipología de Entidades locales y potestad autoorganizatoria.- III. LA SITUACION DE LOS REgLAMENTOS ORGANICOS LOCALES aNTES de La SENTENCIA 214/1989, de 21 de dicIembre, del Tribunal Constitucional.- IV.- La Situacion de los Reglamentos Organicos locaLeS tras la Sentencia 214/1989, de 21 de diciembre, del Tribunal ConstiTUCIONAL.- V. LA INSUFICIENCIA DEL ESOUEMA LEGISLACION BASICA-LEGISLACION DE DESARROLLO PARA ASEGURAR LA AUTONOMIA LOCAL EN MATERIA ORGANIZATIVA.- VI. Reflexiones Finales.

\section{CONSIDERACIONES GENERALES}

La Sentencia núm. 214/1989, de 21 de diciembre, del Tribunal Constitucional (1) ha declarado inconstitucionales una serie de preceptos de la LRBRL, y al hilo de tal declaración ha modificado sustancialmente la posición ordinamental de los Reglamentos orgánicos de las Entidades locales, pues si antes primaban éstos sobre las Leyes autonómicas que, en el ámbito de sus competencias, pudieran dictar las Comunidades Autónomas, ahora, tras el pronunciamiento del intérprete supremo de la Constitución española, este orden de aplicación de normas en materia organizativa y de funcionamiento ha sido

(1) BOE. núm. 10. Suplemento del 11 de enero de 1990. Vid. también el BOE núm. 37, de 12 de febrero de 1990 en el que se publica el Auto dictado por el Tribunal Constitucional el 16 de enero de 1990, para aclarar la Sentencia 214/1989, resolutoria de los recursos $610,613,617$ y $619 / 1985$ 
alterado, de forma que los Reglamentos orgánicos ocupan una posición menos relevante que la que ocupaban antes de la mencionada Sentencia. Por el contrario, la legislación autonómica sobre régimen local tiene, después el fallo, prevalencia sobre los Reglamentos orgánicos locales.

Este cambio, sin duda sustantivo, plantea algunas cuestiones sobre el carácter de la potestad autoorganizatoria de las Entidades locales, así como acerca de la dificultad de articular un sistema en virtud del cual la autonomía constitucionalmente garantizada de las Entidades locales no quede reducida a una simple fórmula engañosa, habida cuenta que las regulaciones autonómicas en su tarea complementadora de la legislación básica estatal pueden desvirtuar seriamente la potestad autoorganizatoria de las Corporaciones locales. $Y$ esta no es cuestión baladí de la cual puede prescindirse sin mayor problema, sino que constituye el núcleo de lo que es la propia autonomía local, $y$, en concreto, de una de sus manifestaciones indeclinables: la potestad autoorganizatoria.

A lo largo de este trabajo intentaremos abordar someramente estas cuestiones, y veremos como el esquema tomado por el Tribunal Constitucional para dar solución al problema que plantea la materia (legislación básica-legislación de desarrollo o complementaria) es insuficiente para configurar una potestad autoorganizatoria efectiva $y$ sin cortapisas que la reduzcan a una mera declaración retórica.

\section{LA POTESTAD AUTOORGANIZATORIA COMO ELEMENTO IM- PRESCINDIBLE DE LA AUTONOMIA LOCAL.}

\section{2,I) Determinaciones previas.}

La nueva organización territorial del Estado, definida y concretada en sus líneas maestras por la Constitución y los Estatutos de Autonomía de las diecisiete Comunidades Autónomas ha supuesto el reconocimiento y la plasmación resuelta de la autonomía de las nacionalidades y regiones que integran la nación española (artículo 2 y Título VIII de la Constitución), así como de las autonomías locales. El reconocimiento de la autonomía tiene unas consecuencias lógicas que no se pueden orillar si no se quiere desnaturalizar al sistema adoptado (un ámbito competencial, una cobertura financiera que haga efectiva la autonomía, una potestad autoorganizatoria, etcétera). Así, por lo que en esta sede interesa, el reconocimiento de la autonomía implica necesariamente la posibilidad de establecer un entramado organizativo que se adapte al ámbito específico sobre el cual se va a desplegar 
esa autonomía. El artículo 148,1-1ํㅡ de la Carta Magna es paradigmático en esta materia (2) en cuanto prevé la asunción de competencias en materia de organización de las instituciones de autogobierno de las Comunidades Autónomas. Y lo prevé en primer lugar, resaltante la importancia de tal competencia. En este sentido, las Entidades locales que tienen constitucionalmente garantizada su autonomía (articulo 137, 140 y 141 de la Norma suprema) (3) necesitan que la misma esté dotada de los elementos imprescindibles para que la autonomía pueda ser efectivamente reputada como tal. Esos elementos son una atribución de poderes o cometidos que les permitan gestionar sus respectivos intereses (artículo 2 LRBRL), una cobertura financiera que haga posible el desarrollo de esos cometidos $y$, evidentemente, una posibilidad real -y no meramente formal- de establecer su propia organización para satisfacer las necesidades colectivas dentro de su ámbito de actuación (cfr. artículo 4 LRBRL). La potestad autoorganizatoria por la cual la Entidad local pueda determinar su propia estructura organizativa adecuada a sus circunstancias geográficas, sociológicas, culturales...es un elemento imprescindible de la autonomía local.

La potestad autoorganizatoria implica, pues, la posibilidad real de definir o determinar el organigrama necesario para el desarrollo de las actividades y el cumplimiento de los fines de las Entidades locales, lo cual se concreta también en la fijación de criterios rectores que sirvan para el funcionamiento de tales Entidades. De ahí que, como señala FERNANDEZ FARRERES (4), la potestad de autoorganización de las Entidades locales se manifiesta en la libertad de organización y en la libertad de funcionamiento. Ahora bien, esta libre disponibilidad que tienen las Entidades locales en el ordenamiento jurídico para establecer su organización y las líneas de fuerza de su funcionamiento tiene que insertarse inexcusablemente en el marco jurídico general determinado por los principios y valores constitucionales, y, en especial, por las prescripciones contenidas en el llamado "bloque de la constitucionalidad", pues si bien la autonomía que tienen las Entidades locales está

(2) Este precepto dice:

"Las Comunidades Autónomas podrán asumir competencias en las siguientes materias:

$1^{a}$ Organización de sus instituciones de autogobierno (...)".

(3) Si bien no se puede comparar-como es obvio- la autonomía politica de las Comunidades Autónomas con la autonomia de las Entidades locales, ya que ambas son cualitativamente diferentes (SSTC.3/1981, de 2 de febrero, y 32/1981, de 28 de julio).

(4) "la potestad local de autoorganización: contenido y límites", en Tratado de Derecho Municipal I, Madrid, 1988, p. 739. 
protegida por la técnica germana de la garantía institucional, lo que comporta que se les otorga una "específica y cualificada protección constitucional a unas concretas instituciones" (5); y que, debido a ello, habrá que atribuirles un elenco sustantivo de competencias y una capacidad efectiva para autoorganizarse, no debe olvidarse que esa.autonomía de las Entidades locales "no es soberanía" (STC. de 2 de febrero de 1981) y, además, tampoco es equiparable a la autonomía política de las Comunidades Autónomas, ya que tiene unos límites más estrictos y una funcionalidad distinta. La autonomia local ha sido definida por el Tribunal Constitucional, quizá con no demasiada previsión (6), como autonomía administrativa (7). Pero esta calificación no supone, en modo alguno, derogar el contenido claramente político que tienen las organizaciones locales, sino que implica que el desenvolvimiento de la misma "sólo puede tener manifestaciones jurídico-administrativas, es decir, la de la norma reglamentaria y el acto administrativo, básicamente" (8). Entonces es evidente que la potestad autoorganizadora de las Entidades locales (artículo 4,1-a) LRBRL) no significa una libertad de disposición absoluta en la configuración de su organigrama administrativo y de sus reglas o criterios rectores de funcionamiento. La autoorganización está limitada por la naturaleza propia de la autonomía local, que comporta el respeto a los valores y principios constitucionales (pluralismo político, solidaridad, participación democrática, eficacia, descentralización, etcétera) (9), así como a la configuración que otras instancias hagan, tanto en la determinación de su ámbito competencial como de los criterios básicos de su organización y funcionamiento.

Es destacable de forma particular la configuración que hacen las instancias estatal y autonómica en tanto que el Texto constitucional en su articulo 149,1-18 dispone que: "El Estado tiene competencia exclusiva sobre (...) las bases del régimen jurídico de las Administraciones públicas $(\ldots)^{\prime \prime}$. Y es claro que dentro de la cate-

(5) Vid. L. PAREJO ALFONSO, Garantía institucional y autonomias locales, Madrid, 1981, p. 116. También, M. SANCHEZ MORON, La autonomía local. Antecedentes históricos y significado constitucional, Madrid, 1990, pp. 161 y ss.

(6) Cfr. M. SANCHEZ MORON, op. cit., pp. 174-178; y. A. TORRES DEL MORAL, Principios de derecho Constitucional Español 2, Madrid, 1988, pp. 338 y 339.

(7) SSTC. 3 y 32/1981, de 2 de febrero y 28 de julio, respectivamente.

(8) L. PAREJO ALFONSO-J.A. SANTAMARIA PASTOR, Informe solicitado por. el Gobierno de Canarias con motivo de la elaboración de la Ley de Régimen Jurídico de las Administraciones Públicas de Canarias, Instituto de Estudios de Administración Local (inédito), Madrid-Santa Cruz de Tenerife, 1984, p. 12.

(9). Vid., a título ejemplificativo, artículo 1,$1 ; 14 ; 23 ; 103 ; 138$ etcétera. 
goría genéricamente "régimen jurídico de las Administraciones públicas" hay que incluir a la Administración local. Esto implica que como el Estado tiene competencia sobre las bases, es decir, tiene poderes para determinar las normas de validez general "que crean un común denominador normativo, un derecho que responde al principio de unidad como límite a la diversificación a que de lugar la pluralidad de ordenamientos jurídicos en nuestro sistema constitucional" (10), las Entidades locales, por de pronto, verán limitada su potestad autoorganizatoria por las bases que dicte el Estado, stricto sensu. Pero no puede omitirse que el binomio legislación básica estatal-legislación de desarrollo de las Comunidades Autónomas otorga un importante papel a estas últimas; papel que en la materia que analizamos -como mạ́s adelante apreciaremos-, podria traducirse pura y simplemente en un vaciamiento de la potestad autoorganizatoria establecida en el artículo 4,1-a) de la LRBRL.

\section{2,2) Tipología de Entidades locales y potestad autoorganizato- ria.}

Si leemos con atenciọ́n los capítulos primero ("Principios generales") y segundo ("De la Administración local") del título VIII de la Constitución española de 27 de diciembre de 1978, dedicado, como se sabe, a la Organización Territorial del Estado, observamos como se mencionan dos tipos de Entes locales: la provincia (artículo 1.37 y 14.1) y el municipio (artículo 137 y 140); y, de una forma más tangencial, se hace referencia también a otro tipo de Ente local (artículo. 141,4); la isla. Es decir, la Carta Magna menciona a un grupo de Entidades locales cuya autonomía queda garantizada ope Constitutionis. Así, la LRBRL, siguiendo este criterio constitucional, distingue las Entidades locales que aparecen configuradas como necesarias e indispensables dentro de la economía del sistema (municipio, provincia e isla) de otro grupo de Entes locales cuya existencia tiene un tratamiento jurídico distinto $y$, por ende, una protección menos intensa que las mencionadas expresamente por el legislador constituyente.

En efecto, el artículo 3 de la LRBRL establece:

(10) Cfr. I. DE OTTO Y PARDO, Estudios sobre Derecho estatal y autonómico, Madrid, 1986, p. 108; y F. TOMAS Y VALIENTE, El reparto constitucional en la Jurisprudencia del Tribunal Constitucional. Madrid, 1988, pp. 108 y ss. También las SSTC. de 28 de julio de 1981 y 7 de abri! e 1983, entre otras muchas. 
“1. Son Entidades locales territoriales:

a) El Municipio.

b) La Provincia.

c) La Isla en los archipiélagos balear y canario.

2. Gozan, asimismo, de la condición de Entidades locales:

a) Las Entidades de ámbito territorial inferior al municipal, instituidas o reconocidas por las Comunidades Autónomas, conforme al artículo 45 de esta Ley.

b) Las comarcas u otras Entidades que agrupen varios Municipios, instituidas por las Comunidades Autónomas de conformidad con esta Ley y los correspondientes Estatutos de Autonomía.

c) Las Areas metropolitanas.

d) Las Mancomunidades de Municipios".

Se observa cómo el precepto distingue claramente los dos grupos e tipos de Entidades locales. En el primer apartado (artículo 3,1) se establecen las Entidades locales a las cuales la Constitución reconoce y garantiza su existencia y autonomía. Califica a este tipo de Entidades como "Entidades locales territoriales". Por el contrario, el apartado segundo (artículo 3,2) lo dedica la Ley a otra clase de Entidades locales que pueden ser supra o inframunicipales, pero que tiene un tratamiento jurídico, en cuanto a su institución o su reconocimiento, bien distinto al que tienen las Entidades mencionadas en el artículo 3,1 LRBRL (11).

Congruentemente con este distinto tratamiento el artículo 4 de la LRBRL reconoce la potestad autoorganizatoria de manera expresa para las Entidades locales territoriales (artículo 4,1). Sin embargo, a las restantes Entidades locales menores, comarcas, mancomunidades de municipios, Entidades que agrupan a varios municipios, áreas metropolitanas ...) sólo les reconoce una mera posibilidad de atribución de la potestad autoorganizatoria, como se deduce de lo dispuesto en el artículo 4,2, según el cual:

“Lo dispuesto en el número precedente podrá ser de aplicación a las Entidades territoriales de ámbito inferior al municipio $y$, asimismo, a las Comarcas, Areas metropolitanas y demás Entidades locales, debiendo las leyes de las Comunidades Autónomas con-

(11) Vid. J. DOMINGUEZ-ALCAHUD Y MONGE, "Tipologia de los Entes locales", en Organización Territorial del Estado (Administración local), Madrid, 1985, pp. 78-83. 
cretar cuáles de aquellas potestades serán de aplicación".

Luego, sólo las Entidades locales territoriales (municipios, provincias e islas) tienen reconocida resueltamente la potestad autoorganizatoria. El resto de las Entidades que no tengan tal carácter la tendrán en la medida que las Leyes de las respectivas Comunidades Autónomas las establezcan.

\section{LA SITUACION DE LOS REGLAMENTOS ORGANICOS LOCALES ANTES DE LA SENTENCIA 214/1989, DE 21 DE DICIEMBRE, DEL TRIBUNAL CONSTITUCIONAL.}

A pesar de que el esquema legislación básica estatal-legislación de desarrollo de las Comunidades Autónomas hubiera determinado que fueran éstas las encargadas de definir o complementar las bases estatales, la LRBRL de 2 de abril de 1985 no siguió este criterio para evitar que la potestad autoorganizatoria de las Entidades locales quedase reducida a un simple nominalismo, sin virtualidad operativa alguna. Por ello la solución que adopta el legislador básico de régimen local de 1985 es la de primar -en orden a la autonomía-, la potestad autoorganizatoria de los Entes locales en perjuicio de la legislación complementaria o de desarrollo que, dentro del marco de sus competencias, las Comunidades Autónomas pudiesen dictar. De suerte que con arreglo a la normativa básica de régimen local los Reglamentos orgánicos locales son los que asumen el cometido de desarrollar, de pormenorizar los criterios generales o básicos establecidos en la propia Ley, y la normación de las Comunidades Autónomas desempeña un papel supletorio de las disposiciones consignadas en la legislación básica y en los correspondientes Reglamentos orgánicos. Con ello se trataba de dar auténtica operatividad a la autonomía local en la materia. Por tanto, la premisa de la que parte esta solución legislativa es correcta, porque lo que se persigue es que la potestad autoorganizatoria no quede convertida por virtud del binomio legislación básica estatal-legislación de desarrollo autonómica, en papel mojado. Para ello se arbitró una solución que obviamente no era la más satisfactoria para los Entes autonómicos (ansiosos de asumir más poderes), pero que sin duda se mostraba como las más apta para respetar ta autonomía local (12).

Asi el artículo 5 LRBRL (declarado por la Sentencia inconstitucio-

(12) En el mismo sentido G. FERNANDEZ FARRERES, op. cit., p. 745, para quien la premisa de la que parte la LRBRL "no es desacertada", ya que si se tiene en cuenta "que constitucionalmente no se ha querido "entregar" definitivamente y en exclusiva el "régimen local" a las Comunidades Autónomas y dada la singularidad misma de la materia organización y funcionamiento de las Entidades locales dotadas de autonomía (...)" 
nal en su totalidad) establecía:

“Las Entidades locales se rigen en primer término por la presente Ley y además:

A)En cuanto a su régimen organizativo y de funcionamiento de sus órganos:

Por las Leyes de las Comunidades Autónomas sobre régimen local y por el Reglamento orgánico propio de cada Entidad en los términos previstos en esta Ley. (...)".

Esta disposición había que ponerla en conexión con otros preceptos de la Ley básica. En concreto, con los artículos 20 y 32 LRBRL, que para los municipios y provincias, respectivamente, consignaban -después de desglosar los órganos necesarios de estas Entidades locales territoriales-, lo siguiente:

“Art. 20,1-c) El resto de los órganos complementarios de los anteriores, se establece y regula por los propios Municipios en sus Reglamentos orgánicos, sin otro límite que el respeto a la organización determinada por esta Ley.

2. Sin perjuicio de lo dispuesto en la regla c) del número anterior, las leyes de las Comunidades Autónomas sobre régimen local podrán establecer una organización complementaria de la prevista en este texto legal, que regirá en cada Municipio en todo aquello que su Reglamento orgánico no disponga lo contrario. (...)".

Y para las provincias el artículo 32,2 disponia:

“El resto de los órganos, complementarios de los anteriores, se establece y regula por las propias Diputaciones sin otro límite que el respeto a la organización determinada por esta Ley. No obstante, las Leyes de las Comunidades Autónomas sobre régimen local podrán establecer una organización provincial complementaria de la prevista en este texto legal, que regirá en cada Provincia en todo aquello en lo que ésta no disponga lo contrario, en ejercicio de su potestad de autoorganización (...)".

De la lectura de los preceptos transcritos quedaba medianamente clara la prevalencia del Reglamento orgánico sobre la legislación que en el ámbito de sus competencias pudieran dictar las Comunidades Autónomas, lo que suponía que sólo en el supuesto de que la Entidad Local 
no hubiera elaborado y aprobado su Reglamento orgánico, o, en su caso, no hubiera previsto en el mismo determinados aspectos concernientes a la organización y funcionamiento, se aplicaba la legislación autonómica. De forma que "una modesta norma organizativa de un pequeño municipio predomina (predominaba) sobre las Leyes emanadas con el máximo estrépito de soberania" (13). Por otro lado, también la legislación estatal que no tuviere el carácter de básica era de aplicación supletoria, pero su supletoriedad era, además, de segundo grado, es decir, esas normas estatales se aplicaban después de las autonómicas (14).

Todas estas aseveraciones fueron explícitamente consignadas en la Resolución de 27 de enero de 1987 que adoptó la desaparecida Dirección General de Administración Local (hoy sustituida por la de Régimen Jurídico), a fin de aclarar la posición ordinamental del Reglamento de Organización, Funcionamiento y Régimen Jurídico de las Entidades locales, aprobado por el Real Decreto 2568/1986, de 28 de noviembre. $Y$ sin perjuicio de las criticas que puede suscitar esa Resolución (15), lo cierto es que en la misma se contienen algunos criterios que merecen ser reproducidos por su claridad. En particular, cuando dice:

“(...) la normativa que en su día puedan establecer las Comunidades Autónomas, en ejercicio de sus competencias sobre régimen local, tendrá por lo que se refiere a los aspectos de organización y funcionamiento internos de las Entidades locales, un alcance meramente supletorio, a título de ordenación de segundo grado, respecto de los Reglamentos orgánicos adoptados por cada Corporación. Esto se traduce, por lo que hace a la organización y funcionamiento de los órganos básicos (Alcalde, Pleno y, en su caso, Comisión de Gobierno), en que sólo se aplicará la legislación autonómica en defecto de toda normativa autónomamente adoptada por la respectiva Corporación. Y por lo que respecta a la organización complementaria (órganos distintos a los citados), en aplicación de dicha normativa autonómica "en todo aquello en que el Reglamento orgánico no disponga lo contrario" (arts. 20.2 y 32.2 LBRL)."

Asimismo por lo que respecta a la normativa que dicta el Estado, distinta a la de naturaleza básica, la precitada Resolución también le

(13) Asi lo afirmaba R. MARTIN MATEO en "El gobierno municipal", REALA. núm. 227, 1985, p. 427.

(14) G. FERNANDEZ FARRERES, op. cit., p. 752.

(15) Vid. F. SOSA WAGNER, "Los Principios del nuevo Régimen Local", en Tratado de Derecho Municipal 1. ob. cit., p. 102. 
concede el carácter de supletoria, si bien con una supletoriedad de segundo grado, conforme a lo establecido en el artículo 149,3 de la Constitución. Por ello asevera:

"(...) tanto las normas incluidad en el Texto refundido como las que contienen los textos actualizados de los Reglamentos citados en la Disposición Final primera de la Ley 7/1985, de 2 de abril, constituyen derecho estatal de carácter supletorio (art. $149,3 \mathrm{CE}$ ) y su vigencia resulta ser transitoria, pues está condicionada, en términos generales, a la entrada en vigor de la normativa autonómica que venga a sustituirlo".

En consecuencia, la relevancia que el sistema establecido por la LRBRL confería a los Reglamentos orgánicos locales, conducente a plasmar efectivamente su potestad autoorganizatoria, era palmaria; $y$ por ende, la relegación que la legislación autonómica y la normación no básica estatal tenía era evidente. Puesto que sólo operaban en tanto no existiese una regulación específica del Ente local, o bien, de existir ésta, fuera compatible con la misma.

De resultas de todo ello el sistema de fuentes venia determinado por el siguiente orden de prelación:

1ㄴ La legislación básica estatal.

$2^{\circ}$ El Reglamento orgánico que dictara la Entidad local.

3ㄴ La legislación autonómica elaborada y aprobada dentro del ámbito de sus competencias por la Comunidad Autónoma respectiva.

$4^{\circ}$ La legislación estatal no básica de acuerdo con lo prescrito en el artículo 149,3 de la Carta Magna.

La prevalencia de los Reglamentos orgánicos de las Entidades locales hacia posible que estos instrumentos jurídicos, dentro de los límites fijados por la legislación básica estatal, pudieran regular una serie de aspectos o asuntos para adaptar el organigrama local a las circunstancias concretas de tiempo y lugar de la respectiva Entidad. Así, los Reglamentos orgánicos podian establecer una Comisión de Gobierno en aquellos municipios menores de 5.000 habitantes, distribuir las grandes áreas de servicios administrativos de los Ayuntamientos, establecer medios de control y fiscalización nuevos a cargo del Pleno, etcétera; $y$, en definitiva, existía una configuración de la potestad autoorganizatoria coherente con el principio de autonomía local consagrado por la Carta Magna española. 
IV. LA SITUACION DE LOS REGLAMENTOS ORGANICOS LOCALES TRAS LA SENTENCIA 214/1989, DE 21 DE DICIEMBRE, DEL TRIBUNAL CONSTITUCIONAL.

Como ya hemos señalado anteriormente la Sentencia constitucional núm. 214/1989, de 21 de diciembre ha declarado inconstitucionales algunos preceptos de la LRBRL. Por lo que a nuestro análisis interesa hay que destacar la declaración de inconstitucionalidad del artículo 5 en su totalidad, y todas las remisiones al mismo contenidas en la Ley, del inciso final ("sin otro límite que el respeto a la organización determinada por esta ley") del artículo 20,1-c), el inciso ("sin otro limite que el respeto a la organización determinada por esta Ley") del artículo 32,2 del inciso final ("en todo aquello que su Reglamento orgánico no disponga lo contrario") del artículo 20,2, y del inciso final ("que regirán en cada provincia en todo aquello en lo que ésta no disponga lo contrario en ejercicio de su potestad de autoorganización") del artículo 32,2.

Esta declaración de inconstitucionalidad vertida en la Sentencia resolutoria de los recursos que en su día interpusieron los órganos legislativos y ejecutivos de las Comunidades de Cataluña y Galicia viene a establecer un "criterio sustantivo diferente" (16) sobre el orden de prelación de normas reguladoras de la organización y el funcionamiento de las Entidades locales, ya que la declaración de inconstitucionalidad del artículo 5 en su totalidad y, a la sazón, la inconstitucionalidad de algunos incisos de otros preceptos que se relacionaban estrechamente con aquél altera de forma sustancial el sistema de fuentes que en él se establecía.

Así, el Fundamento Jurídico $5^{\circ}$ de la Sentencia dice:

“(...) El precepto impugnado establece el orden de prelación de normas aplicables a las distintas materias que conciernen a la Administración Local, situando en primer lugar los contenidos en la propia Ley, que tiene asi efectivamente una pretensión de superioridad ordinamental, que se hace explícita en su exposición de motivos. En cuanto que enumera las normas aplicables en una materia en la que la competencia legislativa está dividida entre el Estado y las Comunidades Autónomas, el precepto ha de ser entendido, en consecuencia, como una norma interpretativa

(16) A. JIMENEZ-BLANCO CARRILLO DE ALBORNOZ, Doctrina Constitucional sobre Régimen Local. La Sentencia 214/1989, de 21 de diciembre, del Tribunal Constitucional, sobre la Ley de Bases de Régimen Local, Granada, 1990, p. 31. 
de lo dispuesto en el bloque de la constitucionalidad respecto de esta materia. Es esta naturaleza de norma meramente interpretativa, sin contenido material alguno, la que hace el precepto constitucionalmente ilegítimo. El orden de fuentes de un ordenamiento compuesto es el establecido por el bloque de la constitucionalidad, sin que uno de los elementos de esta realidad compuesta, en este caso el legislador estatal, pueda imponer a todos los demás, como única interpretación posible, la que él mismo hace. Es cierto que al usar de sus facultades legislativas sobre las materias de su competencia tanto el Estado como las Comunidades Autónomas han de operar a partir de un determinado entendimiento del bloque de la constitucionalidad. Tal entendimiento, que puede ser también denominado, si se quiere, interpretación, se produce entonces, sin embargo, en conexión con una materia determinada no como criterio abstracto de interpretación y podrá ser siempre corregido por este Tribunal a través de las oportunas vías procesales.

No es éste, sin embargo, como es obvio, el contenido del precepto que ahora analizamos. Prescindiendo de la afirmación preliminar de la prioridad absoluta de la propia L.R.B.R.L. que naturalmente existirá en la medida en la que sus preceptos puedan apoyarse en los títulos competenciales que el Estatuto ostenta, el resto de los párrafos que el artículo $5^{\circ}$ contiene establece como queda dicho un orden de prelación de fuentes que será correcto en la medida en que coincida con lo dispuesto en el bloque de la constitucionalidad, e incorrecto en cuanto se aparte de él. En cuanto tal coincidencia exista el precepto es en consecuencia superfluo y en cuanto no exista inválido. Su anulación no origina por tanto vacío normativo alguno (...)".

Por tanto el Alto Tribunal dice que lo que coincide con el bloque de la constitucionalidad es superfluo, y lo que no coincide es nulo, $y$, en consecuencia, la anulación o expulsión del ordenamiento del artículo 5 LRBRL no produce vacío normativo alguno. El Tribunal Constitucional no abunda más sobre esta trascendental cuestión, y quizás en este punto debió agotar más sus argumentaciones para, de esta forma, esclarecer esta intrincada materia. No avanza nada sobre cuáles son sus criterios materiales sobre el orden de fuentes (JIMENEZBLANCO) (17)

En cualquier caso lo que evidencia este fundamento jurídico 5o, así como el 6 , es que quiere dar mayor protagonismo al papel confi-

(17) Op. cit. .p.41. 
gurador de las Comunidades Autónomas, y adopta para conseguir ese objetivo el binomio legislación básica-legislación de desarrollo.

El Fundamento Jurídico 6을

"Lo que sucede es que en lo concerniente a la organización municipal, el orden constitucional de distribución de competencias se funda en el reconocimiento de tres ámbitos normativos correspondientes a la legislación básica del Estado (artículo $149,1,18$ de la Constitución), la legislación de desarrollo de las Comunidades Autónomas según los respectivos Estatutos y la potestad reglamentaria de los municipios, inherente esta última a la autonomía que la Constitución garantiza en su art. 140(..)".

Es decir, el Tribunal Constitucional se separa resueltamente de la solución adoptada por la LRBRL, según la cual, como ya hemos puesto de relieve, la autonomía constitucionalmente garantizada de las Entidades locales exigía -o, mejor-, aconsejaba, que el esquema legislación básica estatal-legislación de desarrollo autonómica se rompiera en favor de una verdadera potestad autoorganizatoria. $Y$ esta ruptura no se hacía para erosionar la autonomía de las Comunidades Autónomas sino por la propia naturaleza de la materia, que requiere que el principio de autonomía funcione al margen del binomio mencionado. Asi se salvaguardaba la potestad autoorganizatoria de las entidades locales de los tentáculos de las Comunidades Autónomas, enemigas naturales de las Corporaciones locales, como dice expresivamente Antonio JIMENEZ-BLANCO (18). Porque la potestad autoorganizatoria es un elemento trascendental de la autonomía. Constituye el núcleo duro de la misma, y muy difícilmente puede hablarse de autonomía local sin una efectiva capacidad para autoorganizarse. Por eso el artículo $6^{\circ}-1$ de la Carta Europea de Autonomia Local, hecha en Estrasburgo el 15 de octubre de 1985 (19), dispone:

"Sin perjuicio de las disposiciones más generales creadas por la Ley, las Entidades locales deben poder definir por sí mismas las estructuras administrativas internas con las que pretenden dotarse, con objeto de adaptarlas a sus necesidades específicas y a fin de permitir una gestión eficaz". (20).

(18) Op. cit., p. 53.

(19) Se aprobó y ratificó por España el 20 de enero de 1988 (BOE de 24 de febrero de 1989), y entró en vigor el 1 de marzo de 1989.

(20) El subrayado es nuestro. 
Esto significa que es la propia Entidad local (municipio, provincia $o$ isla) (21) la que debe definir las estructuras administrativas internas

(21) A nuestro juicio los argumentos expuestos en el voto particular discrepante de la sentencia 214/1989, de 21 de diciembre del Magistrado Don Eugenio DIAZ EIMIL son también aplicables a las Entidades provinciales e insulares, toda vez que la autonomia de las provincias e islas tiene la misma protección constitucional que la de los municipios. Este voto dice:

"Mi discrepancia con la Sentencia aprobada por la mayoria del Pleno se produce en relación con la inconstitucionalidad parcial de los arts. 20.1 c) y 20.2 , declarada en los apartados c) y d) del número primero del fallo y se fundamenta en las siguientes razones.

El modelo de organización municipal que diseña la Constitución impide reconocer a las Comunidades Autónomas, en esta materia, competencias que no sean estrictamente residuales, pues asi lo impone el respeto a la autonomía municipal consagrada en su art. 140.

Dicho modelo constitucional resulta del equilibrado juego de tres ámbitos normativos distintos cuyos efectos reciprocamente limitados determinan que, en su configuración, deben distinguirse tres diferentes niveles de organización municipal, cuyo correcto orden descendente es, a mi juicio, el siguiente:

1. organización básica, común a todos los Municipios, que corresponde establecer al Estado en ejercicio de la competencia que le atribuye el art. 149.1.18 de la Constitución.

2. Organización complementaria, que corresponde a los propios Municipios en ejercicio de su autonomia, en cuyo núcleo esencial se incluye el poder de autoorganización, y

3. Organización municipal complementaria de la anterior, que corresponde a las Comunidades Autónomas en virtud del art. 148.1.2 de la Constitución y de sus respectivos Estatutos, cuyas normas de atribución de competencias en materia de régimen local deben siempre entenderse, al igual que las del Estado, sometidas al limite que se deriva de la autonomia municipal.

Los arts. 20.1 c) y $\mathbf{2 0 . 2}$ de la Ley impugnada guardan fiel conformidad con ese modelo constitucional, no siendo a mi juicio, aceptable afirmar que tales preceptos legales básicos desplazan indebidamente la competencia autonómica sobre la organización municipal a un plano distinto del que constitucionalmente le corresponde, eliminando la posibilidad de todo espacio normativo para la legislación de desarrollo autonómico en esta materia, puesto que la naturaleza supletoria y residual de esa competencia autonómica viene necesariamente determinada por la garantía de la autonomía municipal, la cual exige de manera insoslayable que las Comunidades Autónomas no puedan cubrir más espacio organizativo municipal complementario que aquel que el Municipio no haya complementado.

Por lo tanto, los citados preceptos legales sitúan la competencia autonómica en materia de organización de los Municipios en el lugar que constitucionalmente le corresponde.

Mantener la tesis contraria de que las Comunidades Autónomas tienen una competencia de organización municipal complementaria que se interpone entre la organización básica establecida por el legislador estatal y la organización complementaria que a las Municipios corresponde en virtud de su autonomía es tanto como reconocer una especie de competencia básica de segundo grado que, aparte de incurrir en la contradicción conceptual de compatibilizar lo básico con lo complementario, altera sustancialmente el modelo constitucional. de organización municipal en la medida en 
sin que esta posibilidad quede desvirtuada o, en el mejor de los casos, condicionada excluyentemente por la legislación complementaria que dicten las Comunidades Autónomas, pues con arreglo a la solución adoptada por la repetida Sentencia constitucional de 21 de diciembre de 1989 la potestad autoorganizatoria corre el peligro de convertirse en una potestad cuasiresidual que sólo opera en la medida que las respectivas Comunidades Autónomas lo permitan.

Cierto es que la propia Sentencia se encarga de subrayar que la potestad legislativa de desarrollo de los Entes autonómicos admite al mismo tiempo la existencia de un ámbito reservado a la autonomía organizativa municipal y provincial (22), pero también es cierto que las Entidades locales en España no tienen, contrariamente a lo que establecen otros ordenamientos jurídicos, como el alemán (23), una vía procesal directa ante el Tribunal Constitucional para interponer un recurso contra una Ley estatal o autonómica que vulnere o contravenga la autonomía local, por lo que hubiera sido más concorde

que admite la posibilidad de que el poder complementario de autoorganización de los Municipios encuentre límites más allá del marco básico establecido por el legislador estatal, que es el único que tiene competencia para establecerlo.

Por consiguiente, estimo que el art. $20.1 \mathrm{c}$ ) en cuanto señala a la legislación básica del Estado como el único límite a la competencia municipal de autoorganización, y el art. 20.2, en la medida que limita la competencia autonómica al espacio de organización complementaria no cubierto por los Reglamentos Orgánicos de los Municipios conjugan de forma intachable el orden constitucional de distribución de competencias con la garantia institucional de la autonomía de los Municipios.

Ello me conduce a entender que dichos preceptos legales son, en su totalidad, constitucionales cualidad que no extiendo al art. 32.2, puesto que considero que seria muy discutible reconocer a la Provincia el mismo nivel de autonomia que al Municipio garantizado en el art. 140 de la Constitución.

Tal es mi opinión que expongo, sin perjuicio del acatamiento y aceptación que me merece la decisión de la mayoria".

(22) Lo mismo se recalca en el Auto aclaratorio dictado por el Tribunal Constitucional el 16 de enero de 1990, cuando dice:"(...) con lo que resulta patente que el Tribunal ha considerado que la potestad municipal de autoorganización ha de observar, en todo caso, lo dispuesto en las normas básicas estatales y las autonómicas de desarro$110, y$ que éstas no pueden en ningún momento desconocer o invadir el espacio dedicado a la autoorganización municipal".

(23) En el sistema germano las Corporaciones locales pueden interponer un recurso contra cualquier Ley emanada de la Federación o de los Estados miembros (Länder) que vulnere la autonomía local, de acuerdo con el artículo 91 de la Ley del Tribunal Constitucional Federal. Por el contrario en el ordenamiento español la única posibilidad que tienen las Corporaciones locales es la que establece el articulo 119 LRBRL, según el cual la Comisión Nacional de Administración Local -órgano de colaboración entre la Administración del Estado y la Administración Local-. "puede solicitar" a los órganos constitucionalmente legitimados la impugnación ante el Tribunal Constitucional de las Leyes del Estado o de las Comunidades Autónomas que pudieran ser lesivas para la autonomia que garantiza la Norma fundamental. 
con dicha autonomía que la resolución se hubiera pronunciado en un sentido más protector, y dejar el orden de prelación de normas aplicables como lo fijó la LRBRL. Ahora, tras la Sentencia del intérprete máximo de la Constitución, cambia la posición de los Reglamentos orgánicos locales, de manera que la legislación de desarrollo que dicten las Comunidades Autónomas ocupa un lugar más importante, y, paralelamente, se produce una disminución de la operatividad de los referidos Reglamentos a los cuales se les confiere un papel cuasiresidual y "complementario de lo complementario".

Esto significa que se sigue con la tradicional tendencia de no reconocer poderes específicos y operativos en materia de organización a las Entidades locales (24), lo que si en otras épocas de la Historia era consecuencia lógica de los condicionantes políticos y jurídicos existentes en esos momentos, en la actualidad, con las virtualidades que anidan en las prescripciones constitucionales, no tiene ninguna justificación, habida cuenta que la autonomía es configuradora de un modelo de Estado, que despliega sus potencias no sólo con respecto a las Comunidades Autónomas, sino también con relación a los Entes locales constitucionalmente garantizados. La autonomía no puede entenderse, pues, como una simple declaración programática de la cual puede prescindirse en la práctica política y administrativa.

En resolución, después de la Sentencia 214/1989, de 21 de diciembre de 1989, del Tribunal Constitucional, el orden de prelación de normas aplicables a esta materia es el siguiente:

1 La legislación básica estatal.

20 La legislación de desarrollo que, en el marco de sus competencias, dicte la correspondiente Comunidad Autónoma.

3은 Los Reglamentos orgánicos de las Entidades locales.

$4^{\circ}$ La legislación estatal de naturaleza no básica, conforme a lo dispuesto en el artículo 149.3 de la Constitución española.

V. LA INSUFICIENCIA DEL ESQUEMA LEGISLACION BASICA-LEGISLACION DE DESARROLLO PARA ASEGURAR LA AUTONOMIA LOCAL EN MATERIA ORGANIZATIVA.

Sin lugar a dudas la resolución del Tribunal Constitucional se apoyó en el esquema legislación básica-legislación de desarrollo o

(24) P. ESCRIBANO COLLADO, "La Autonomia Local en la jurisprudencia del Tribunal Constitucional", en Organización Territorial del Estado (Administración Local, vol. II, ob. cit., p. 1005. 
complementaria para solucionar la cuestión de la posición ordinamental de los Reglamentos orgánicos de las entidades locales, planteada por las Comunidades Autónomas recurrentes al estimar que sus potestades habian sido erosionadas por el juego de los artículos $5 A, 20,1-c$ ) (inciso final), 20,2 (inciso final) y el 32,2 (inciso final y el extremo que reza: "Sin otro límite que el respeto a la organización determinada por esta Ley"). Este esquema, válido para la articulación de los poderes del Estado y las Comunidades Autónomas en otras materias, no es, en cambio, lo suficientemente operativo cuando se aplica miméticamente a la organización y al funcionamiento de las Entidades locales con autonomía constitucionalmente garantizada, porque si se deja que las Comunidades Autónomas sean las que complementen o desarrollen las disposiciones básicas dictadas por el Estado -estrictamente considerado-, se corre el peligro de convertir la potestad autoorganizatoria de las Entidades locales en una cláusula vacia, que funciona todo lo más, como una potestad con una operatividad limitada y condicionada a la "sensibilidad" local que las distintas Comunidades Autónomas pueden tener. Este esquema es, además, inadecuado con la opción que el Texto constitucional adoptó en orden a no interiorizar los Entes locales en las Comunidades Autónomas; ya que, como es bien sabido, el régimen local no se ha atribuido "in totum" a la disponibilidad de los Entes autonómicos. Por ello el Tribunal Constitucional ha declarado el carácter bifronte del régimen jurídico de las autonomias locales (S. de 23 de diciembre de 1982), y, también es corolario de este aserto el que el Estado mantenga relaciones directas con las Entidades locales (25). Como resultado de todo ello es evidente que no es posible una interiorización de las Entidades locales (26) que propugne una disponibilidad tal de las Comunidades Autónomas que desvirtúe lo que, en puridad, es un elemento sustantivo de la autonomía local.

Debe tenerse en cuenta que el principio de autonomia garantizado por la Constitución española (artículo 137, 140 y 141) es, como dice PAREJO ALFONSO (27), "un principio constructivo de un ordenamiento territorial específico", que supone que esta clase de Entidades tenga la cobertura jurídica suficiente para la gestión de sus respectivos

(25) Cfr. L.PAREJO ALFONSO, Estado social y Administración Pública. Los postulados constitucionales de la reforma administrativa, Madrid, 1983, p. 190.

(26) En otros ordenamientos (alemán), si existe una interiorización de los Entes locales, $y$, consecuentemente, la potestad autoorganizatoria está más rigidamente limitada por el Land (vid. F. SOSA WAGNER, "La Autonomía Local”, en REALA. núm. 240, 1988, pp. 1630 y 1631; y L. PAREJO ALFONSO, Derecho Básico de la Administración Local, Barcelona, 1988, pp. 221 y ss.

(27) Derecho Básico de la Administración Local, op. cit., pp. 112-120. 
intereses. Cobertura jurídica que se traduce en un elenco de potestades (ex artículo 4 LRBRL) que deben actuarse con los límites que el ordenamiento establezca. No puede, por tanto, estimarse que la autonomía y la descentralización quedan agotadas con el establecimiento de Comunidades Autónomas y la atribución de poderes a las mismas, y que las Entidades locales son una especie de "parientes pobres y sumisos" del nuevo sistema de organización territorial del Estado a las cuales se les da los residuos que las otras instancias -digamos, con las cautelas que procedan- superiores desechan. Puesto que la autonomia, como se ha dicho, es una técnica de carácter general que configura un modelo de Estado (SSTC. de 28 de julio de 1981 y de 27 de febrero de 1987). De forma que si el artículo 137 de la Constitución establece para todas las Entidades territoriales, sean autonómicas o locales, la autonomía para la gestión de sus respectivos intereses, y si es palmario que la gestión de intereses autonómicos necesita una dotación competencial, estructural y financiera apta para que esa autonomía tenga tal naturaleza; también es claro que la gestión de intereses locales no puede quedar absorbida por la gestión de intereses autonómicos realizada por las Comunidades Autónomas, porque ambas formas de organización -la autonómica y la local-, se superponen pero no se anulan (28).

Entonces, al cambiar el orden de prelación de normas aplicables a la materia que analizamos, la Sentencia del Alto Tribunal da prevalencia a la legislación que dicten las Comunidades Autónomas. Ello significa que los Reglamentos orgánicos locales deberán ajustarse a partir de la sobredicha resolución no sólo a la legislación básica estatal sino a las normas locales que elaboren y aprueben los Entes autonómicos. Ante esta situación normativa la operatividad o innovación que pueden tener los Reglamentos orgánicos se recorta sustancialmente $y$, por ende, más que Reglamentos en los cuales tendrían que anidar muchas potencialidades innovativas para adaptar el organigrama local a las peculiaridades, costumbres, cultura e indiosincracia propia de la respectiva Entidad local, se transforman en Reglamentos "ejecutivos" (29) de las disposiciones que las Comunidades Autónomas dicten.

(28) L. PAREJO ALFONSO, Derecho Básico de la Administración Local, cit., p. 119.

(29) Es tradicional la clasificación que la doctrina científica hace de los Reglamentos por su relación con la Ley, según la cual existen Reglamentos extra legem (Los Reglamentos independientes), secundum legem (-los ejecutivos que desarrollan y ejecutan la Ley) y contra legem (los de necesidad que se dictan para hacer frente a una circunstancia excepcional). Pues bien, los Reglamentos ejecutivos o secundum legem son los más condicionados por la Ley y, a la sazón, son los que menos maniobrabilidad dejan a la Administración pública. pero, paradójicamente, son los Reglamentos de organización los que dejan mayor margen para operar a la Administración, la cual 
Por consiguiente, la aplicación del esquema legislación básica-legislación de desarrollo a la organización y al funcionamiento de las Entidades locales supone un recortamiento efectivo y excesivo de la potestad autoorganizatoria que el ordenamiento les reconoce como expresión inderogable de su autonomia. Disminución que deja a la autonomia en una posición más precaria, de suerte que si las correspondientes Leyes autonómicas no tienen la suficiente sensibilidad con respecto a esta materia (y existen ejemplos que ilustran que la sensibilidad de los legisladores territoriales con respecto a la autonomía local no es siempre la más deseable) muy bien podría convertirse la autonomía local, por lo que respecta al menos en esta materia, en un instituto desdibujado y sólo aparentemente respetado.

\section{REFLEXIONES FINALES}

A lo largo de las precedentes líneas hemos observado cómo la Sentencia constitucional núm. 214/1989, de 21 de diciembre ha supuesto una alteración sustancial del orden de prelación de normas aplicables a la organización y al funcionamiento de las Entidades locales con autonomía constitucionalmente garantizada, pues, al declarar inconstitucionales una serie de artículos e incisos de la Ley básica estatal de 2 de abril de 1985, ha reforzado diáfanamente el poder de las Comunidades Autónomas en detrimento de la potestad autoorganizatoria de las Entidades locales. Para el reforzamiento de la posición de los Entes autonómicos se ha recurrido, como se ha advertido, a la aplicación del esquema legislación básica estatal-legislación de desarrollo de las Comunidades Autónomas. Esquema que en si mismo es operativo y eficaz para la vertebración de poderes del Estado y de las Comunidades Autónomas en otras materias o sectores de la acción pública, pero que aplicado a la materia analizada desnaturaliza considerablemente uno de los elementos inescindibles de la

\footnotetext{
puede configurar su estructura organizativa interna. El mayor radio de operatividad se fundamenta en que estos Reglamentos agotan sus efectos dentro del propio ámbito de la Administración. (operan "ad intra"). Y son los Reglamentos de organización los típicos Reglamentos independientes (STS. de 11 de abril de 1981) (vid. R. PARADA VAZQUEZ, Derecho Administrativo I. Parte General, 2 de., Madrid, 1990, pp. 58 y 59; y E. GARCIA DE ENTERRIA-T.R. FERNANDEZ RODRIGUEZ, Curso de Derecho Administrativo I, $4^{\mathbf{E}}$ de., Madrid, 1983, pp. 213-215). Esto nos lleva a que al ser el ámbito organizativo el que mayor autonomía permite a la Administración, resulta contraproducente limitar tanto (legislación básica-legislación complementaria autonómica) la potestad autoorganizatoria de las Entidades locales, ya que los criterios básicos o uniformes están lo suficientemente explicitados en la normativa básica estatal.
} 
autonomía local constitucionalmente garantizada: la potestad autoorganizatoria.

La Sentencia constitucional de 21 de diciembre de 1989 modifica la -a nuestro juicio- acertada solución que arbitró el legislador estatal en la LRBRL con el juego de los artículos 5,20 y 32 ; y con esta alteración las posibilidades reales (no las formales o las imaginables) de una gestión autónoma de los intereses propios de las Entidades locales (municipios, provincias e islas) que sea respetuosa con los principios constitucionales, entre los cuales ocupa un lugar preeminente el de autonomia, se recortan hasta límites excesivos, que son incompatibles con la necesaria autoorganización de los Entes.

Es evidente que las Comunidades Autónomas deben establecer regulaciones sobre régimen local para que las competencias que el bloque de la constitucionalidad les ha conferido se desenvuelvan eficazmente. Pero esta potenciación del rol de las normaciones autonómicas tiene su campo más propio en otro tipo de Entidades locales distintas a los municipios, provincias o islas; Entidades locales a las cuales la misma Sentencia constitucional les reconoce un fuerte grado de "interiorización" autonómica, y que, por tanto, sobre ellas cabe una mayor disponibilidad de las Comunidades autónomas en orden a su reconocimiento, dotación competencial y estructura. Todo ello, claro, es, sin perjuicio del desarrollo de otras atribuciones que tengan con respecto a las otras Entidades con autonomía constitucionalmente garantizada (municipios, provincias e islas). Por ello hubiera sido deseable que la potestad autoorganizatoria de municipios, provincias $\mathrm{e}$ islas hubiera quedado menos limitada.

En otro orden de consideraciones es de destacar que en el propio Tribunal Constitucional se pronunciaron voces sobre el peligro que la potestad autoorganizatoria municipal corre con la solución vertida en el fallo. Pero el voto discrepante sólo atiende a los municipios, no extiende, por tanto, sus argumentaciones a las provincias e islas; Entidades, estas últimas, con idéntica protección constitucional que los municipios, al margen de que la entidad provincial tenga poca virtualidad operativa en algunas Comunidades Autónomas -como sucede en Canarias-, o que no tenga un arraigo parangonable al de los municipios o al de otro tipo de Entes locales -como acontece en Cataluña-. Con todo, es ilustrativo este voto discrepante de la dificultad que la materia tiene y de los problemas que genera el fallo. Puesto que por encima de afirmaciones puramente formales (como decir que en todo caso la legislación autonómica deberá respetar la autonomía local); lo cierto es que el papel asignado a la potestad autoorganizatoria de las Entidades locales es insuficiente. No vale decir, por otra parte, que hasta cierto punto la solución de la Sentencia es congruente con la 
pasividad que hasta el momento han mostrado las Entidades locales, que no han aprobado muchos Reglamentos de esta clase; habida cuenta que hasta fechas recientes las Entidades locales tenían una nula autonomia, carecian de unos mecanismos de defensa de sus competencias frente a las constantes invasiones del Estado y sobre ellas se ejercian unas rígidas técnicas de tutela, lo que hacía que las mismas fuesen unos "meros instrumentos del Estado" (SOSA WAGNER) (30). En cambio, el ordenamiento vigente, con la Constitución como cabeza y guía del mismo, no puede permitir que se mantengan planteamientos de la misma naturaleza. Es necesario una autonomía local efectiva, para cual la autoorganización es un elemento consustancial.

\section{ABREVIATURAS UTILIZADAS}

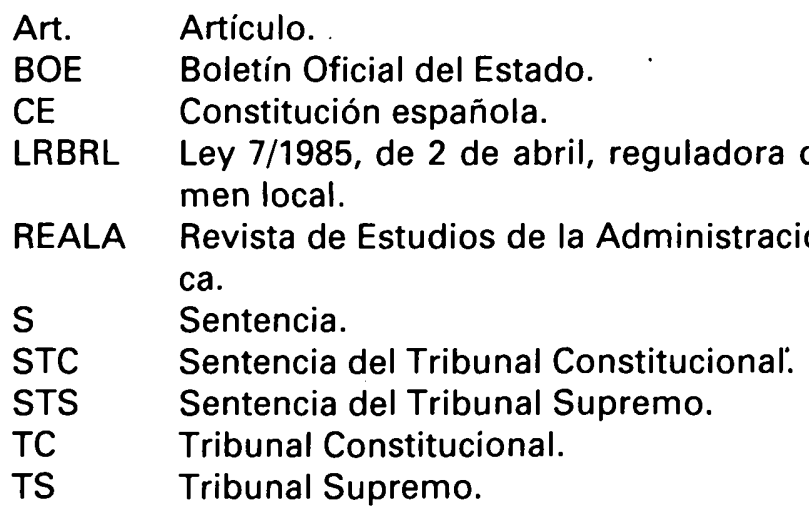

(30) Manual de derecho Local, Madrid, 1987, p. 46. 
REALA-1991, núm. 252. SARMIENTO ACOSTA, MANUEL JESUS. LA POSICION ORDINAMENTAL D...

REALA-1991, núm. 252. SARMIENTO ACOSTA, MANUEL JESUS. LA POSICION ORDINAMENTAL D... 